\title{
A Psicologia Social no campo da cultura material
}

Ulpiano T. Bezerra de Meneses

Departamento de História, Faculdade de Filosofia, Letras e Ciências Humanas/Universidade de São Paulo

Helga Dittmar. The Social Psychology of material possessions. To have is to be. Hemel Hempstead: Harvester Wheatsheaf/New York: St. Martin's Press, 1992.

O livro recente de Helga Dittmar - ampliação de sua Tese de Doutorado em Psicologia na Universidade de Sussex, em 1990 - trata da posse de objetos e, já no tífulo, procura acentuar a possibilidade de a cultura material constituir objeto privilegiado de conhecimento psicológico: A Psicologia Social das posses materiais.

Ora, os vínculos entre os estudos de cultura material e a Psicologia, particularmente a Psicologia Social, continuam a ser tênues e fragmentados. Com efeito, se a Psicologia sempre mobilizou maciçamente dados do mundo material para montar e encaminhar suas questões próprias, é ainda bastante reduzido o número de obras que tratam a cultura material de um ângulo especificamente psicológico. Mais raros, ainda, são os trabalhos que podem fornecer quadros gerais de referência, dentro da Psicologia, para os diversos aspectos da cultura material. Seria uma exceção o caso de Helga Dittmar?

A menção a algumas obras, de largo curso entre historiadores, antropólogos e sociólogos especializados nos estudos de cultura material parece-me pertinente, se quisermos melhor situar o trabalho de Dittmar. Por certo conviria apenas aludir àquelas obras que, direta ou indiretamente tratam, como aqui, desse problema tão caro à Psicologia, o eu e a identidade, em suas dimensões individual e social.

Uma dessas é, sem dúvida a obra de Csikszentmihalyi \& RochbergHalton (1981), cujo título, indefinido e ambicioso, "O significado das coisas", 
ainda que temperado por um subtítulo mais prudente, "Símbolos domésticos e o eu", sem dúvida assegurou com certa prioridade vasta circulação a seus temas e enfoques. Nela, os autores trabalharam com um horizonte constituído por famílias da área metropolitana de Chicago e, servindo-se de categorias como "cultivation" |segundo a qual o significado envolve um processo ativo de interpretação atraído por objetivos), personificação das coisas, reificação dos objetos, etc., analisam uma listagem de mais de um milhar e meio de artefatos domésticos, para entender "things as role models or socializing signs" (p.XII). Tendo como pano de fundo um referencial não apenas psicológico, mas também social, que vai de Durkheim a Hannah Arendt, desenvolvem os autores a perspectiva de que não apenas "things people use, own, and surround themselves with might quite accurately reflect aspects of the owner's personality" - o que, afinal das contas soa banal -, mas, ainda, são "part of one's self, not in any mystical or metaphorical sense but in cold concrete actuality" (Csikszentmihalyi \& Rochberg-Halton 1981: 14-5). Essa perspectiva (de que aliás os autores não são a matriz original, mas que neles ganha realcel, cada vez mais vai-se tornando rotina. Um dos dois autores, aliás, em artigo de síntese (Csiksżentmihalyi 1993) numa coletânea de introdução aos estudos de cultura material, de certa forma resume estas conclusões, ao apresentar - entendimento da Psicologia sobre o papel do artefało na objetivação e estabilização do eu, seja demonstrando o poder do proprietário, seja revelando a continuidade do eu ao longo do tempo, seja alocando cada sujeito numa rede social, como símbolos de relações e critérios de valor, classificações.

Nesse passo, não é de estranhar que Perinbanayagam (1990) tenha podido escrever um artigo intitulado "How to do self with things" lartigo aliás insatisfatório por colocar o problema da retórica dos artefatos sem resolvê-lo a contento). Nem que os estudos que procuram explorar a dimensão do gênero na cultura material, cada vez mais numerosos (p.ex., Kirkham, ed.1996 ou De Grazia \& Furlough, eds. 1996), tenham privilegiado tal concepção do eu expresso, expressivo e extensor, com relação aos objetos materiais. Peter Lunt, aliás, ao fazer um balanço das variedades de pesquisas psicológicas sobre consumo, não deixou de reconhecer "a shift of emphasis in recent research on ownership and possessions away from the notion that goods provide symbolic utility and act as signs of status, towards an exploration of the way that goods provide opportunities for self-expression and personal development" (Lunt 1995: 249). Nesta vertente de estudos, que tem como eixo o consumo - sem dúvida a vertente mais fecunda destes últimos anos - tais problemas têm sido colocados e examinados segundo as mais diversas variáveis e se a questão do self nem sempre é axial, sempre tem merecido a atenção devida (cf. Lunt \& Livingstone 1992).

Estas poucas menções, servem para mostrar a centralidade dos problemas de que se ocupa o livro de Dittmar. Não há, pois, nenhuma novidade temática ou iluminação de abordagem. O fato de tal livro ser o objeto do presente ensaio crítico significaria, então, tatar-se de um marco qualquer num território já percorrido? Lamentavelmente, não. O livro é correto, sério, competentemente elaborado e se assenta numa bibliografia impressionante (quase 600 títulos!), além de mobilizar um sem-número de pesquisas e estudos de caso, de base experimental, entre os quais os que a própria autora realizou. Mas a força de 
pensamento é precária e a originalidade é restrita. No entanto, merece registro e leitura, pois constitui súmula confiável e um repertório de referências da maior utilidade, fonte preciosa de informações. E se mencionaremos a seguir, para caracterizar suas carências, estudos, a meu ver, melhor qualificados que o seu, relativos aos mesmos temas nucleares, não é tacanhamente para lhe fazer cobranças bibliográficas (vários títulos são posteriores a 1992; por outro lado, seu domínio bibliográfico é irrepreensivel, embora utilizado de forma caleidoscópica e superficiall, mas para demonstrar que caminhos mais convenientes já estão abertos e frutificando.

Por essa ambigüidade que a obra representa, justifica-se que se retrace a trajetória que ela desenvolve, assim como, também, que se assinalem, cautelarmente, as lacunas e deficiências que já se anunciaram. De fato, trata-se mais de lacunas e deficiências do que de proposições insustentáveis, pois o corpo nuclear de seus postulados e proposições me parece plenamente aceitável.

$O$ livro se inicia com uma questão crucial, que se imaginaria seu eixo condutor: ter é ser, ao menos é o que se vem verificando na sociedade ocidental. Contudo, ao invés de um equacionamento próprio de questão assim tão polimorfa e cheia de consequêencias, Dittmar apenas pincela generalidades, extraídas principalmente de Erich Fromm. $O$ objetivo, parece, não é mais que introduzir um de seus Leitmotiven, a identidade pela posse de bens materiais. Por isso, questões complexas, de suma pertinência, como sociedade de consumo de massa, fetichismo, etc., são introduzidas como num videoclipe, sem deixar marcas profundas, após cessado o estímulo provocador.

Já o segundo capítulo apresenta interesse para estudiosos da cultura material (e outros campos afins) não familiarizados com a literatura psicológica. Aqui a autora aborda a possibilidade de contar com explicações biológicas para - "sentimento" e comportamentos de posse e propriedade. Discute, assim, com bastante adequação e recurso a pesquisas empíricas, o alegado "instinto aquisitivo", que descarta como chave para o entendimento de um fenômeno que é, antes, essencialmente social.

A seguir já entra num dos pontos-chave de seu argumento, ao introduzir a noção de "extended self" e tomar os objetos materiais não somente como "refletindo" ou "expressando" a identidade, mas também como "parte" dela, instrumentos de autodefinição e afirmação, de controle e poder. llgnoro aqui, para fins práticos imediatos, distinções que não me pareceram suficientemente explicitadas ou fundamentadas entre "eu" e "identidade" e o conteúdo técnico de "self"). Embora discuta superficialmente a dicotomia "instrumental/simbólico", para descartála, acentua, adequadamente, o caráter instrumental e simbólico das posses materiais como extensão da identidade. Novamente apenas de passagem são apontadas questões, como a da mercadoria, das quais não se extrai nenhuma linha sólida de entendimento.

No quarto capítulo a autora se reporta a premissas conceituais que estão na base de seu trabalho, cuja perspectiva ela identifica como sendo o "construcionismo social", de filiações múltiplas, entre as quais a construção social do conhecimento de Berger, Goff, Schütz, o behaviorismo social da escola de Chicago, principalmente o interacionismo de G. H. Mead, Gerger, etc. $\bigcirc$ que se está declarando é que o "significado" das coisas nem é imanente a elas, nem 
se produz fora da interação social. É, portanto, historicamente gerado e historicamente se transforma: é variável socio-culturalmente. Em outras palavras, é aqui que se enraiza a perspectiva das posses materiais "as socially shared symbols for identity" (p.66), estabelecendo-se, por isso, uma tensão "self/society" que a autora não chega a desenvolver. (Para isso teria sido necessário que ela enfrentasse questões de grosso calibre, como o problema da metáfora linguística na cultura material - que ela liquida em uma página e meia - ou a matriz ou matrizes de sentido numa dialética eu/sociedade, ou a conveniência de abandonar o conceito de "representações sociais", na linha Moscovici-Jodelet, etc.).

Contudo, este capítulo é crucial, não só porque coloca, a meu ver numa boa direção, as abordagens de Dittmar, mas também, ao inverso, porque cria responsabilidades e exigências que ela não cumpre ou cumpre mal. Assim, em lugar de procurar um objeto epistemológico próprio para sua pesquisa de Psicologia Social e apenas depois inserito num cenário social lo que seria transferir o problema da identidade para o interior da própria Psicologia...., ela caminha no tratamento de uma dimensão psicológica de fenômenos sociais. Fica, porém, na exibição de sementes desta posição fecunda, mas que não vingaram todas.

Os capítulos 5 e 6 constituem, por assim dizer, o âmago substantivo da obra. Neles são abordadas, mais de forma espiralada que linear linclusive repetindo incansavelmente coisas já ditas e repisadas), as posses como expressões simbólicas da identidade e as posses materiais como reflexos da identidade. Mais explicitamente, as posses materiais aparecem como localizadores sócio-materiais e instrumentos de percepção e construção da realidade social. Aqui entram referências de todo tipo, parataticamente, mostrando que, além de suas filiações teóricas declaradas, a autora admite qualquer gênero de ecletismo. Por isso, estes troncos centrais parecem uma mini-enciclopédia com verbetes sobre status, o dom, consumo, gênero, classes sociais, ideologia, estereótipo, motivações e expectativas, etc. etc. Acredito, sem desprezo, que é precisamente nesse tratamento enciclopédico que esta obra deva ser capitalizada, e proveitosamente. Com efeito, se a teia de implicações é escamoteada e se a coerência teórica é flexivel, e se, além disso, as questões são, o mais das vezes referenciadas mas não discutidas até uma configuração satisfatória, o elenco de problemas, as pistas para desenvolvimentos futuros, a bibliografia, os estudos de caso, os problemas metodológicos, etc. etc., constituem manancial que compensa pragmaticamente as insuficiências e indefinições.

Os dois últimos capítulos introduzem questões amplas, que deveriam funcionar como ponto de chegada dos diversos encaminhamentos e propostas. $O$ primeiro se refere ao impacto do contexto material na identidade percebida.Segundo a autora, desloca-se a atenção do actor para o viewer como se o viewer não fosse, sempre, também um actor... Seja como for, esse afunilamento restritivo vai de par com a confissão, pela autora, de que o liame entre identidade e realidade sóciomaterial é "somewhat ambiguous, potentially ideological in nature and articulated only implicitly" (p. 184).

O segundo destes capítulos, ao enfocar a concepção ocidental de identidade e o paradoxo (sic) materialismo-idealismo, retoma, sem muito avanço e 
com tons idealistas, a questão inicial: ser ou ter? A frase final do livro dá um pouco o tônus geral da obra:

"...material social reality is an integral, pervasive aspect of everyday social life, of constructing ourselves and others. Therefore it merits to be investigated in its broad implications for self-definition, other-perception and interactions with the physical and social environment. These are concerns not only for psychologists, but also for sociologists, anthropologists, economists and other social scientists. Only a truly interdisciplinary perspective can hope eventually to contextualize the individual in material terms, and thus move closer to a comprehensive understanding of the implications the materialistic orientation of Western culture has for everyday social reality" (p.206).

Além dessa necessária interdisciplinaridade, creio que também um balizamento interno mais completo e rigoroso teria melhor conduzido aos rumos propostos. Cumpre, assim, examinar, ainda que sumariamente, algumas lacunas que marcam a obra, limitando-nos, é claro apenas àquilo que seria exigência do título e objetivos apresentados.

A primeira insuficiência referé-se à própria indefinição com que se caracteriza isso que é a pedra de toque do trabalho: as posses materiais. A autora tanto fala de posse quanto, menos freqüentemente, de propriedade, sem clarificar a especificidade que cada expressão possa conter e, mesmo, sem traçar uma linha divisória suficientemente nítida entre, por exemplo, "posses" materiais e a expressão genérica e neutra "cultura material". Há um vínculo aí implícito,entre as coisas materiais e outro polo que oscila entre o indivíduo, o "eu", os agentes sociais, grupos sociais, a sociedade.

De início impõe-se questionar quais "posses materiais" estão em jogo. Por que, por exemplo, a exclusão do corpo? Que o corpo integra a trama da cultura material, não se põe hoje em dúvida. E se se pretendesse que ele está distante do temário de Dittmar, basta lembrar, para desmenti-lo, uma obra editada por Pelchevsky, Ginzburg \& Rapp (1994) que explora, numa "revisão feminista", precisamente o corpo como propriedade. E outras posses físicas, como os alimentos, por que, também, ignorá-los se hoje eles são ingrediente estratégico na vertente do consumo nos estudos de cultura material, particularmente quando estão em tela o gosto, a moda, sem esquecer, é claro, a identidade? Iver Gronow 1997, que é recente mas deriva de um filão mais antigo, ou então, Fine, Heasman \& Wright, eds., 1996). Enfim, mais grave que tudo, por que afastar de sua plataforma de análise a moeda? Ela não é posse material, não é, como pretende, entre tantos outros Dagognet (1992: 187-2201 o "objeto dos objetos"? E que vínculos? Quais os polos e as formas de vinculação e respectivos efeitos? Que graus de associação? Goffman, por exemplo, para analisar o potencial de expressão de status, que ele julgava presente em qualquer artefato, trabalhou com gradações (que, a bem da verdade, não dizem respeito apenas à questão da posse) em noções, instrumentos de análise e categorias que envolvem variáveis tão interessantes como estima, estigma, alteridade e estranhamento, "desidentificação", uso oficial e idiossincrático, "facilitadores sociais", objetos ocupacionais (como "role distancing devices"), etc. (cf Riggins 1990).

Na perspectiva do "interacionismo simbólico", compreende-se mal que a autora tenha tratado tais questões com tanta negligência e sem nenhuma 
sistemática. A preocupação com os aspectos expressivos das interações produtoras de sentido fez com que ela desconsiderasse alguns atributos seminais daquilo que Amariglio \& Callari (1983: 2121 , referindo-se ao reconhecimento da propriedade na sociedade burguesa, chamam de "objectification through which agents are defined as selves differentiated from others".

A indefinição do que seriam "posses" ou "propriedades" materiais repercute, assim, num caráter quase autônomo, avulso, abstrato, dos objetos presentes na discussão. Sintoma significativo foi ter-se relegado o problema da coleção - para nada dizer do colecionismo - para menções rápidas e superficiais. Ora, não se trata de problema novo neste campo. Há mais de dez anos, Virginia Dominguez, resenhando livros sobre ou pertinentes a coleções, concluía que o valor delas não residia em princípio nas suas representações do outro, mas, antes, podiam ser lidas como "referential indices of the self" (Dominguez 1986: 554). Quase ao mesmo tempo, Gifford (1985) já falava, num trabalho reiteradamente citado, das coleções antropológicas como constando de "objects and selves". Hoje, tal enfoque é corriqueiro (Elsner \& Cardinal, eds., 1994; Pearce 1995).

A problemática da coleção, de imediato nos conduz àquela do mercado, inclusive do chamado mercado dos bens simbólicos. Afinal, como pretende Belk (1995), colecionar é uma forma particular de consumo. Claro que, na perspectiva do livro em exame, seria na problemática do consumo (por Dittmar várias vezes mencionada, mas jamais desenvolvidal que estaria a sinalização mais adequada para discutir o mercado.

Evidentemente, não é só com a coleção e o colecionismo que se deve trabalhar, na ótica do consumo nos estudos de cultura material. Já na década de 80, alguns textos capitais, como os de McCracken (1988) ou a coletânea de Appadurai (1986) abriram sendas. Hoje, há um verdadeiro boom em que se avolumam os trabalhos e os exemplos podem ser multiplicados lapenas para citar alguns casos mais dignos de menção: Bronner, ed. 1987; Ewen 1988; Fine \& Leopold 1993; Brewer \& Porter, eds. 1993; Douglas \& Isherwood 19961. Em todas as obras aqui mencionadas, a problemática da identidade é nevrálgica ou, então, goza de um lugar relevante. "You are whał you shop" é um slogan da década de 60 a que alude Shields (ed. 1992) e que bem poderia ser colocado em confronto com o "You are what you have" inscrito até no subtítulo da obra de Dittmar. Os problemas que Shields e seus colaboradores levantam, ainda que vinculados essencialmente d̀ contemporaneidade e, em particular, ao pósmodernismo, teriam esclarecido muitos tópicos em penumbra no livro de Dittmar as "shopping cultures", a estética do consumo e os novos modos de subjetividade, as relações interpessoais e os respectivos modelos de totalidade social, o gênero e o mercado como espetáculo, etc. etc.

Em parte, em Dittmar, a abstração desse campo de forças do mercado pode ser explicada pelo interesse restrito que ela demonstra em relação à problemática do valor, praticamente ausente de seu horizonte prioritário - com inevitáveis conseqüências limitadoras. Ela restringe-se a tratar do valor pragmático, quase sempre em dicotomia com o valor simbólico. Ora, como falar de posse e propriedade, nas sociedades geradas após o século XVIII, sem falar, como tantos já fizeram, após Marx, de valor de uso e valor de troca, além, doutra parte, de valor cognitivo e valor sígnico, de valor afelivo e assim por diante. Daí 
ser difícil explicar que uma obra voltada para o esclarecimento dos significados e funções sócio-psicológicos das posses e propriedades - e que de quebra tenha "possuir = ser" como um de seus motes - transforme mecanismos como a fetichização e a "comodificação" das coisas materiais em alusões desencontradas, esparsas e puramente circunstanciais.

Por essas insuficiências todas, apesar da contribuição aproveitável que traz (e do título sedutor que ostenta), este não é ainda, infelizmente, o livro capaz de assegurar uma adequada cartografia da análise psicológica no campo da cultura material.

\section{BIBLIOGRAFIA CITADA}

AMARIGLIO, Jack, CALLARI, Antonio. Marxian value theory and the problem of the subject. In: APTER, Emily, PIETZ, William (Eds.) Fetisbism as cultural discourse. Ithaca: Cornell University Press, 1993. p.186-216.

APPADURAI, Arjun (Ed.) The social life of things: commodities in cultural perspective. Cambridge: Cambridge University Press, 1986.

BELK, Russel W. Collecting in a consumer society. London: Routledge, 1995.

BREWER, John, PORTER, Roy (Eds.) Consumption and the world of goods. London: Routledge, 1993.

BRONNER, Simon J. (Ed.) Consuming visions: accumulation and display of goods in America, 1880-1920. New York: Norton, 1989.

CLIFFORD, James. Objects as selves. An afterword. In: STOCKING, Jr., George W. (Ed.) Objects and otbers: essays on museums and material culture. Madison: The University of Wisconsin Press, 1985. p.236-46.

CSIKSZENTMIHALYI, Mihaly. Why we need things. In: LUBAR, Steve \& KINGERY, W. David (Eds.) History from things: essays on material culture. Washington: Smithsonian Institution Press, 1993. p.20-9.

CSIKSZENTMIHALYI, Mihaly, ROCHBERG-HALTON, Eugene. The meaning of things: domestic symbols and the self. Cambridge: Cambridge University Press, 1981.

DAGOGNET, François. Philosopbie de la propriété: l'avoir. Paris: Presses Universitaires de France, 1992.

DE GRAZIA, Victoria, FURLOUGH, Ellen (Eds.) The sex of tbings: gender and consumption in historical perspective. Berkeley: University of California Press, 1996.

DOMINGUEZ, Virginia. The marketing of heritage, American Ethnologist, v.13, n.3, p.546-55, Aug. 1986. 
DOUGLAS, Mary, ISHERWOOD, Baron. The world of goods: towards an Anthropology of consumption. 2.ed. London: Routledge, 1996. (1.ed. 1979).

ELSNER, John, CARDINAL, Roger (Ed.) The cultures of collecting. London: Reaktion Books, 1994.

EWEN, Stuart. All consuming images: the politics of style in contemporary culture. s.l., Basic Books, 1988.

FINE, Ben, LEOPOLD, Ellen. The world of consumption. London: Routledge, 1993.

FINE, Ben, HEASMAN, Michael, WRIGHT, Judith. Consumption in the age of affluence: the world of food. London: Routledge, 1996.

GRONOW, Jukka. The Sociology of taste. London: Routledge, 1997.

KIRKHAM, Pat (Ed.) The gendered object. Manchester: Manchester University Press, 1996.

LUNT, Peter K. Psychological approaches to consumption: varieties of research, past, present and future. In: MTLLER, Daniel (Ed.) Acknowledging consumption: a review of new studies. London: Routledge, 1993. p.238-63.

LUNT, P. K., LIVINGSTONE, S. M. Mass consumption and personal identity. Milton Keynes: Open University Press, 1992.

MCCRACKEN, Grant. Culture and consumption: new approaches to the symbolic character of consumer goods and activities. Bloomington: Indiana University Press, 1988.

PEARCE, Susan M. On collecting: an investigation into collecting in the European tradition. London: Routledge, 1995.

PERINBANAYAGAM, R. S. How to do self with things. In: RIGGINS, Stephen H. (Ed.) Beyond Goffman: studies on communication, institution, and social interaction. Berlin: Mouton De Gruyter, 1990. p.315-40.

PETCHEVSKY, R.; GINZBURG, F., RAPP, R. (Eds.) The body as property: a feminist re-vision. Berkeley: University of California Press, 1994.

RIGGINS, Stephen Harold. The power of things: the role of domestic objects in the presentation of self. In: RIGGINS, S. H. ed. Beyond Goffman: studies on communication, institution, and social interaction. Berlin: Mouton De Gruyter, 1990. p.341-68.

SHIELDS, Rob (Ed.) Lifestyle shopping. The subject of consumption. London: Routledge, 1992. 
Psicologia Social e Cultura Material

Ulpiano T. Bezerra de Meneses

O A. avalia a contribuição de Helga Dittmar em The Psychology of material possessions. To have is to be, ao estudo psicológico da cultura material. Apresenta-se rapidamente um histórico da pesquisa sobre as posses materiais como um "eu estendido". A despeito da utilidade do livro como um repositório de informações de todo tipo, esta não é ainda a obra de síntese, tão necessária, sobre o potencial da Psicologia Social no estudo da cultura material, em virtude das muitas lacunas, assim como de um tratamento superficial e enciclopédico de várias questōes-chave.

UNITERMOS: Cultura Material. Posses materiais. Psicologia Social.

Anais do Museu Paulista, N.Sér, v.4, p.283-90, jan./dez.1996

Social Psychology and Material Culture

Ulpiano T. Bezerra de Meneses

The A. appraises Helga Dittmar's contribution to the psychological understanding of material culture (The Psychology of material possessions. To have is to bel. A short historical background is given for the study of material possessions operating as an "extended self". In spite of its usefulness as a repertoire of information of all kinds, Dittmar's book is not yet the much needed synthesis of Social Psychology's potential for a deeper knowledge of material culture, due to several gaps as well as to the cursory and encyclopaedic treatment of many central issues.

UNITERMS: Material Culture. Material possessions. Social Psychology.

Anais do Museu Paulista, N.Sér. v.4, p.283-90, jan./dez.1996

Prática do espaço, experiência do corpo: Sennett e a cidade

Marta Mega de Andrade

Este ensaio tem por eixo a obra de Richard Sennett, Flesh and stone. The body and the cily in Western civilization. Salienta algumas questöes centrais na obra de Sennett: a relação entre a história global e a perspectiva local; os usos ou "formas de fazer como formas de produzir". Embora não seja preocupação central de Sennett, são investigadas implicações destas questões no campo dos estudos da cultura material, especialmente a possibilidade de um paradigma discursivo na análise espacial das práticas corporais.

UNITERMOS: História Urbana. História do corpo. Corpo e espaço.

Anais do Museu Paulista, N.Sér. v.4, p.291-308, jan./dez.1996

Spatial practices and bodily experience: Sennett and the city

Marta Mega de Andrade

This essay focuses on Richard Sennett's Flesh and stone. The body and the cily in Western civilization. It stresses some of the central questions in Sennett's book: the relationship between a global history and a local perspective; "uses" or "ways of doing" as ways of producing. Although not Sennett's main concern, implications of these questions in the field of material culture studies are investigated, especially the possibility of a discursive paradigm in the analysis of spatial practices and bodily experiences.

UNITERMS: Urban History. History of the body. Body and space

Anais do Museu Paulista, N.Sér. v.4, p.291-308, jan./dez.1996 